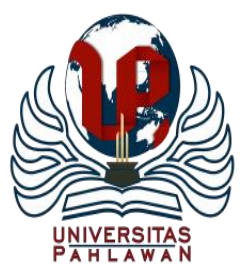

Jurnal Basicedu Volume 5 Nomor 1 Tahun 2021 Halaman 383-394

JURNAL BASICEDU

Research \& Learning in Elementary Education

https://jbasic.org/index.php/basicedu

\title{
Keterampilan Pengucapan Kata Melalui Model Pembelajaran Cooperative Integrated Reading and Composition bagi Anak Berkesulitan Belajar
}

\author{
Fifi Melani Putri ${ }^{1}$, Marlina Marlina ${ }^{2}$ \\ Pendidikan Luar Biasa, Fakultas Ilmu Pendidikan, Universitas Negeri Padang, Indonesia ${ }^{1,2}$ \\ E-mail: fifimelaniputri@gmail.com ${ }^{1} \underline{\text { lina_muluk@ fip.unp.ac.id }}^{2}$
}

\begin{abstract}
Abstrak
Penelitian ini dilatar belakangi dari permasalahan yang ditemukan oleh peneliti dimana peneliti menemukan seorang anak yang mengalami kesulitan dalam belajar. Permasalahan ini ditemukan di SD N 34 Siguntur Tua anak tersebut sudah berumur 12 tahun namun belum lancar dalam membaca. Penelitian ini bertujuan untuk membuktikan pengaruh model pembelajaran CIRC dalam meningkatkan keterampilan pengucapan kata bagi anak berkesulitan belajar kelas IV di SD N 34 Siguntur Tua. Jenis penelitian ini eksperimen dalam bentuk single subject research dengan desain A-B-A, subjek penelitian seorang anak berkesulitan belajar dengan kondisi anak sering menambahkan huruf dan menggantikan huruf dalam membaca. Teknik pengumpulan data dalam penelitian ini menggunakan tes. Teknik tes dilakukan dengan cara menugaskan anak membaca kata dengan tepat setelah diberikan intervensi dengan model pembelajaran CIRC. Data dianalisis menggunakan teknik visual grafik. Dari penelitian yang telah dilakukan didapatkan hasil bahwa model pembelajaran CIRC dapat meningkatkan keterampilan pengucapan kata anak berkesulitan belajar kelas IV di SD N 34 Siguntur Tua sesuai dengan hasil analisis data dalam kondisi dan antar kondisi.
\end{abstract}

Kata Kunci: Model Pembelajaran CIRC, Pengucapan Kata, Anak Berkesulitan Belajar

\section{Abstract}

This research was motivated by the problems found by the researcher where the researcher found a child who had difficulty learning. This problem was found in Elementary, the child was 12 years old but was not yet fluent in reading. This study aims to prove the effect of the CIRC learning model in improving word pronunciation skills for children with learning difficulties in grade IV at Elementary. This type of research is experimental in the form of Single Subject Research with A-B-A design, the research subject of a child has difficulty learning with the condition that the child often adds letters and replaces letters in reading. Data collection techniques in this study using tests. The test technique is done by assigning children to read words correctly after being given intervention with the CIRC learning model. Data were analyzed using visual graph techniques. From the research that has been done, it is found that the CIRC learning model can improve the pronunciation skills of children having difficulty learning in grade IV at Elementary in accordance with the results of data analysis in conditions and between conditions.

Keywords: CIRC Learning Model, Word Pronunciation, Children with Learning Difficulties

Copyright (c) 2021 Fifi Melani Putri, Marlina Marlina

Corresponding author

Address : Siguntur Tua

ISSN 2580-3735 (Media Cetak)

Email : fifimelaniputri@gmail.com

ISSN 2580-1147 (Media Online)

DOI: https://doi.org/10.31004/basicedu.v5i1.666 
387 Keterampilan Pengucapan Kata Melalui Model Pembelajaran Cooperative Integrated Reading and Composition bagi Anak Berkesulitan Belajar - Fifi Melani Putri, Marlina Marlina

DOI: https://doi.org/10.31004/basicedu.v5i1.666

\section{PENDAHULUAN}

Pengetahuan dan keterampilan dapat diperoleh melalui pendidikan (Tristiantari \& Sumantri, 2016). Pendidikan dapat diperoleh dari jenjang pendidikan PAUD, TK, SD, SMP, SMA dan sampai perguruan tinggi. Salah satu pendidikan formal di jenjang pendidikan dasar adalah pembelajaran bahasa. Dalam pembelajaran bahasa peserta didik dituntut untuk bisa membaca dengan baik. Keterampilan dasar fundamental yang harus dikuasai anak dan salah satu bidang pelajaran yang cukup penting disekolah adalah membaca (Marlina, 2019). Dikatakan cukup penting karena hampir seluruh mata pelajaran disekolah melibatkan aspek membaca.

Kelancaran membaca berpengaruh terhadap hasil prestasi akademik peserta didik. Maka peserta didik yang berkesulitan belajar khusus pada membaca akan mengalami ketertinggalan pembelajaran dibandingkan teman-teman lainnya yang sudah lancar dalam membaca. Anak kesulitan belajar tidak bisa menunjukkan kemajuan yang berarti dibidang keterampilan akademik dasar seperti membaca, menulis, dan berhitung (Marlina, 2019). Anak kesulitan belajar memiliki intelegensi normal tetapi menunjukkan satu atau beberapa kekurangan dalam proses belajar (Novembli, Marlina, \& Martias, 2015). Kesulitan belajar bisa di sebabkan berbagai faktor baik internal maupun eksternal. Salah satu faktor yang sangat berpengaruh yang menyebabkan anak menjadi kesulitan belajar adalah lingkungan belajar dan kurangnya motivasi dalam belajar. Ketika faktor lingkungan tidak sesuai dengan kapabilitas dan minat anak maka kesulitan belajar akan terjadi (Marlina, 2019).

Berdasarkan hasil observasi yang di lakukan di SD N34 Siguntur Tua peneliti menemukan seorang anak yang mengalami kesulitan dalam belajar. Anak tersebut kurang bersemangat dalam belajar, anak juga sering mengganggu temannya dalam belajar, dan anak tersebut juga sudah tiga kali tinggal kelas. Dalam belajar anak cenderung meniru dan menyalin tulisan yang ada di papan tulis tanpa tahu maksud tulisan tersebut. Ketika membaca anak mengalami kesulitan dalam membaca berupa penambahan huruf pada kata dan pergantian huruf pada kata. Padahal keterampilan membaca anak yang duduk di kelas IV seharusnya sudah sampai pada membaca pemahaman namun keterampilan membaca anak masih pada kata atau membaca permulaan. Untuk mengatasi permasalahan tersebut maka peneliti menggunakan model pembelajaran CIRC untuk meningkatkan keterampilan pengucapan kata anak kesulitan belajar. Salah satu teknik pembelajaran berbasis pada kerjasama yang dirancang untuk mengembangkan kemampuan membaca dan menulis adalah model pembelajaran CIRC (Durukan, 2011). Model pembelajaran ini cocok diterapkan untuk memecahkan masalah pembelajaran, khususnya untuk pembelajaran membaca dan menulis. Selain itu, model pembelajaran CIRC memiliki tujuan utama, yaitu menggunakan kelompok-kelompok kooperatif untuk membantu satu teknik pembelajaran berbasis pada kerjasama, yang dirancang untuk mengembangkan kemampuan membaca dan 
388 Keterampilan Pengucapan Kata Melalui Model Pembelajaran Cooperative Integrated Reading and Composition bagi Anak Berkesulitan Belajar - Fifi Melani Putri, Marlina Marlina

DOI: https://doi.org/10.31004/basicedu.v5i1.666

menulis pesera didik dalam mempelajari kemampuan dalam memahami bacaan yang dapat diterapkan secara luas (Marlina, 2015).

Pada saat menerangkan pelajaran guru memakai metode ceramah dalam menjelaskan pelajaran sehingga guru masih menjadi pusat pembelajaran. Guru tidak memberikan perhatian khusus kepada anak kesulitan belajar padahal anak tidak paham dengan maksud bacaan yang diberikan. Sehingga ini menyebabkan tujuan pembelajaaran tidak bisa tercapai dengan baik. Model pembelajaran CIRC dipilih karena banyak peneliti sebelumnya yang menggunakan model pembelajaran ini untuk pembelajaran bahasa terkhusus membaca. Menurut (Shoimin, 2016) CIRC memiliki kelebihan yaitu sangat tepat untuk meningkatkan keterampilan siswa dalam menyelesaikan soal pemecahan masalah, dominasi guru dalam pembelajaran berkurang, siswa termotivasi pada hasil secara teliti karena bekerja dalam kelompok, para siswa dapat memahami makna soal dan saling mengecek pekerjaannya, membantu siswa yang lemah, dan meningkatkan hasil belajar khususnya dalam menyelesaikan soal yang berbentuk pemecahan masalah. Kekurangan dari model pembelajaran CIRC yaitu tidak bisa digunakan untuk matapelajaran yang berhubungan dengan hitung-hitungan. Tentunya model pembelajaran ini bisa membangkitkan motivasi belajar anak berkesulitan belajar. Dengan model pembelajaran CIRC anak berkesulitan belajar yang biasanya malas membaca dan kurang motivasi akan lebih bersemangat karena proses belajarnya akan dilaksanakan dalam bentuk kelompok sehingga teman-teman yang lainnya bisa membantu anak berkesulitan belajar dalam menghadapi kesulitan yang dihadapi oleh anak tesebut..

Model pembelajaran CIRC membantu guru dan peserta didik agar semua berhasil menjadi pembaca yang efektif (Gupta \& Ahuja, 2014). Melalui penerapan model pembelajaran ini peserta didik akan lebih mudah menemukan dan memahami pemecahan konsep-konsep yang sulit jika mereka saling mendiskusikan masalah yang dihadapi dengan teman sebayanya. selain itu, model pembelajaran ini mampu meningkatkan cara berpikir kritis, kreatif, serta menumbuhkan rasa sosial yang tinggi serta mampu menguasai pelajaran (Yantini, Sudiara, \& Astika, 2014). Intervensi model pembelajaran CIRC ini bertujuan agar keterampilan pengucapan kata anak berkesulitan belajar dapat meningkat.

\section{METODE}

Penelitian ini menggunakan metode eksperimen yang berbentuk single subject research (SSR). Eksperimen merupakan suatu bentuk penelitian yang dilakukan secara sengaja guna mengetahui dampak dari pemberian treatment atau perlakuan terhadap subjek penelitian (Jaedun, 2011). Penelitian ini menggunakan desain A-B-A. Penelitian ini dilakukan di SD N34 Siguntur Tua dengan subjek penelitian seorang anak kelas IV SD yang berkesulitan belajar. Teknik pengumpulan data dalam penelitian ini dilakukan melalui tes. Teknik tes dilakukan dengan cara menugaskan siswa membaca 30 kata dengan tiga pola kata berbeda yaitu KVK, VKVK, dan KVKVK dengan tepat setelah diberikan intervensi 
389 Keterampilan Pengucapan Kata Melalui Model Pembelajaran Cooperative Integrated Reading and Composition bagi Anak Berkesulitan Belajar - Fifi Melani Putri, Marlina Marlina

DOI: https://doi.org/10.31004/basicedu.v5i1.666

dengan menggunakan model pembelajaran CIRC. Model pembelajaran CIRC dilakukan dengan cara membentuk peserta didik menjadi kelompokkelompok belajar yang beranggotakan 4 orang. Kemudian peserta didik diberikan soal berupa kalimat rumpang dan peserta didik diminta melengkapi kata yang hilang pada kalimat tersebut dengan cara berdiskusi. Kemudian peserta didik berkesulitan belajar diminta membacakan hasil diskusi kedepan kelas dan teman-teman yang lain diminta mendengarkan setiap kata yang dibaca anak kesulitan belajar. Kemudian jika ada kata yang salah maka setiap teman yang lainnya bertugas membantu memperbaiki hasil bacaan anak berkesulitan belajar. Alat pengumpulan data yang dipakai dalam penelitian ini adalah format pengumpulan data pada kondisi baseline dan intervensi. Penulis mengukur langsung kemampuan awal (baseline) siswa dalam pengucapan kata. Alat ukur yang digunakan adalah persentase kemudian data dianalisis dengan visual grafik dan dianalisis pada setiap fase.

\section{HASIL DAN PEMBAHASAN}

\section{Hasil Penelitian}

Penelitian ini dilakukan sebanyak 17 kali pertemuan, dimana kondisi baseline (A1) dilakukan sebanyak lima kali pertemuan, kondisi intervensi (B) dilakukan sebanyak delapan kali pertemuan dan pada kondisi baseline (A2) dilakukan sebanyak empat kali pertemuan. Berikut ini data perbandingan antara kondisi baseline (A1), kondisi intervensi (B) dan kondisi baseline (A2) :

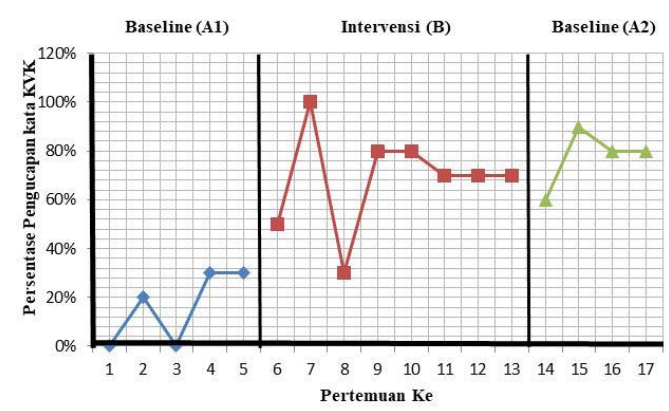

Grafik 1. Analisis dalam kondisi pengucapan kata KVK

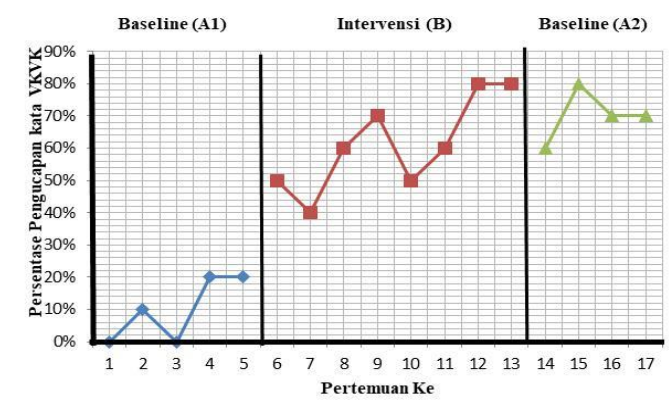

Grafik 2 Analisis dalam kondisi pengucapan kata VKVK

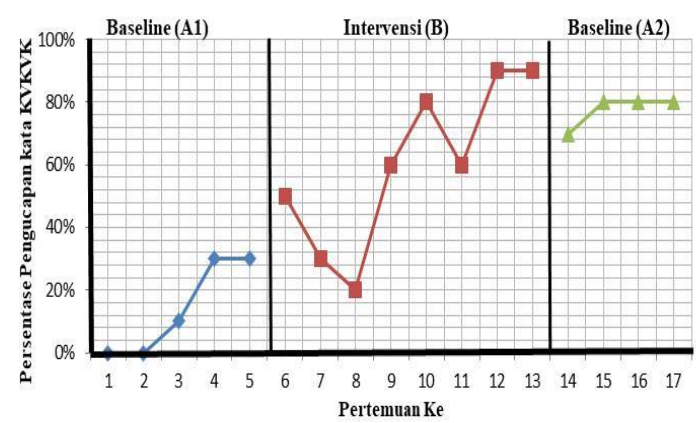

Grafik 3 Analisis dalam kondisi pengucapan kata KVKVK

Keterangan :

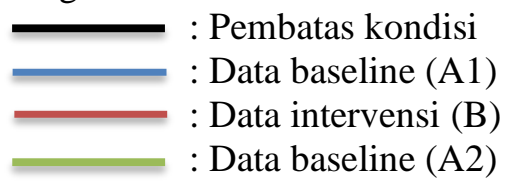

Berdasarkan grafik 1.1 dapat dilihat bahwa keterampilan pengucapan kata pola KVK anak 
390 Keterampilan Pengucapan Kata Melalui Model Pembelajaran Cooperative Integrated Reading and Composition bagi Anak Berkesulitan Belajar - Fifi Melani Putri, Marlina Marlina

DOI: https://doi.org/10.31004/basicedu.v5i1.666

berkesulitan belajar melalui model pembelajaran CIRC pada pertemuan pertama sampai kelima mendapat persentase $0 \%, 20 \%, 0 \%, 30 \%, 30 \%$. Mean level pada kondisi baseline (A1) adalah 16. Batas atas pada kondisi baseline (A1) ini adalah 17,2 sedangkan batas bawahnya 14,8 . Persentase stabilitasnya adalah $0 \%$. Karena data A1 sudah stabil maka dilakukan intervensi (B) berupa pemberian model pembelajaran CIRC. Panjang kondisi pada fase intervensi adalah 8 dengan mean level 68, 75. Batas atas pada kondisi intervensi (B) ini adalah 74,75 sedangkan batas bawahnya 62,75 . Persentase stabilitas pada kondisi intervensi yaitu $37,5 \%$. Dengan diberikannya perlakuan estimasi kecenderungan arah pada kondisi ini meningkat. Karena kondisi anak setelah diberikan intervensi sudah stabil kemudian peneliti melanjutkan pada kondisi baseline (A2) dengan panjang kondisi 4 dan mean level 77,5. Batas atas pada kondisi baseline (A2) ini adalah 84,25 sedangkan batas bawahnya 70,75 . Persentase stabilitasnya adalah $50 \%$. Persentase kecendrungan arah pada baseline kedua ini mengalami peningkatan.

Selanjutnya berdasarkan grafik 1.2 keterampilan pengucapan kata pola VKVK anak berkesulitan belajar melalui model pembelajaran CIRC pada pertemuan pertama sampai kelima mendapat persentase $0 \%, 10 \%, 0 \%, 20 \%, 20 \%$. Mean level pada kondisi baseline (A1) adalah 10. Batas atas pada kondisi baseline (A1) ini adalah 13 sedangkan batas bawahnya 7. Persentase stabilitasnya adalah $20 \%$. Karena data A1 sudah stabil maka dilakukan intervensi (B) berupa pemberian model pembelajaran CIRC. Panjang kondisi pada fase intervensi adalah 8 dengan mean level 61,25. Batas atas pada kondisi intervensi (B) ini adalah 67,25 sedangkan batas bawahnya 55,50. Persentase stabilitas pada kondisi intervensi yaitu $25 \%$. Persentase stabilitas pada kondisi intervensi yaitu 25\%. Dengan diberikannya perlakuan estimasi kecenderungan arah pada kondisi ini meningkat. Karena kondisi anak setelah diberikan intervensi sudah stabil kemudian peneliti melanjutkan pada kondisi baseline (A2) dengan panjang kondisi 4 dan mean level 70. Batas atas pada kondisi baseline (A2) ini adalah 67,25 sedangkan batas bawahnya 55,50. Persentase stabilitasnya adalah $50 \%$. Persentase kecendrungan arah pada baseline kedua ini mengalami peningkatan.

Pada grafik 1.3 keterampilan pengucapan kata pola KVKVK anak berkesulitan belajar melalui model pembelajaran CIRC pada pertemuan pertama sampai kelima mendapat persentase $0 \%, 0 \%, 10 \%, 30 \%, 30 \%$. Mean level pada kondisi baseline (A1) adalah 14. Batas atas pada kondisi baseline (A1) ini adalah 16,25 sedangkan batas bawahnya 11,75. Persentase stabilitasnya adalah $0 \%$. Karena data A1 sudah stabil maka dilakukan intervensi (B) berupa pemberian model pembelajaran CIRC. Panjang kondisi pada fase intervensi adalah 8 dengan mean level 60. Batas atas pada kondisi intervensi (B) ini adalah 66,75 sedangkan batas bawahnya 53,25. Persentase stabilitas pada kondisi intervensi yaitu $25 \%$. Dengan diberikannya perlakuan estimasi kecenderungan arah pada kondisi ini meningkat. Karena kondisi anak setelah diberikan intervensi sudah stabil kemudian peneliti melanjutkan pada kondisi baseline (A2) dengan panjang kondisi 4 
391 Keterampilan Pengucapan Kata Melalui Model Pembelajaran Cooperative Integrated Reading and Composition bagi Anak Berkesulitan Belajar - Fifi Melani Putri, Marlina Marlina

DOI: https://doi.org/10.31004/basicedu.v5i1.666

dan mean level 70. Batas atas pada kondisi baseline (A2) ini adalah 83,50 sedangkan batas bawahnya 71,50. Persentase stabilitasnya adalah $75 \%$. Persentase kecendrungan arah pada baseline kedua ini mengalami peningkatan.

Data kemudian dianalisis melalui analisis antar kondisi dalam meningkatkan keterampilan pengucapan kata anak berkesulitan belajar dengan menggunakan intervensi model pembelajaran CIRC. Berikut ini data analisis antar kondisi :

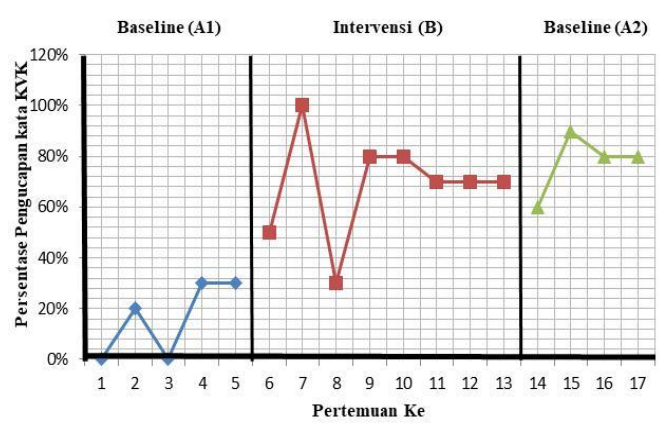

Grafik 1.4 Analisis antar kondisi pengucapan kata KVK

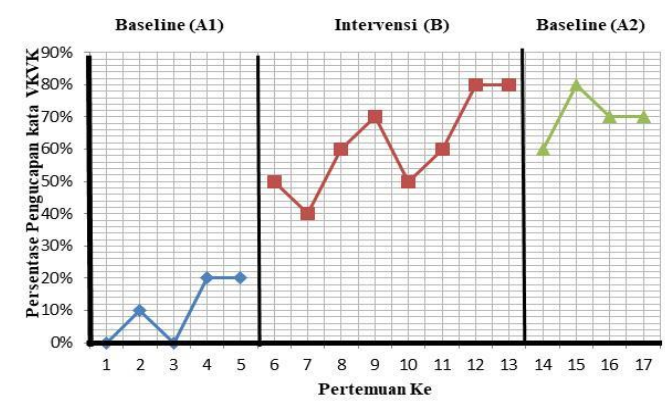

Grafik 1.5 Analisis antar kondisi pengucapan kata VKVK

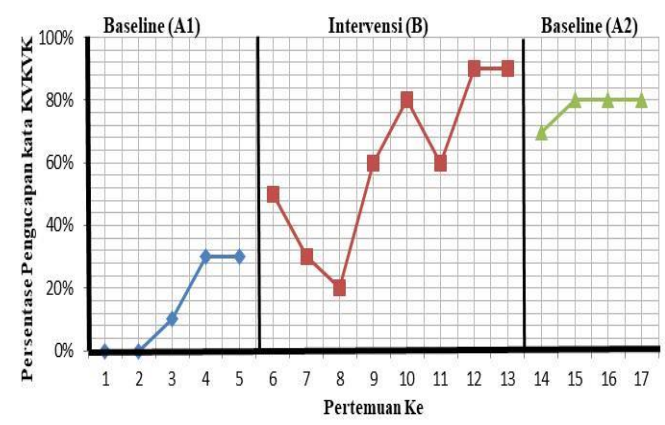

Grafik 1.6 Analisis antar kondisi pengucapan kata

\section{KVKVK}

Keterangan :

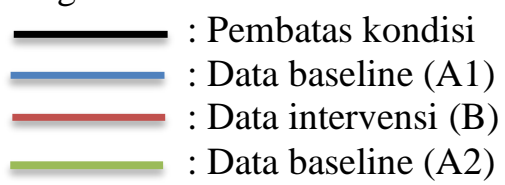

Analisis antar kondisi merupakan jumlah variabel yang berubah yaitu satu dengan target behaviour pengucapan kata. Berdasarkan grafik 1.4 antar kondisi di atas dapat dijelaskan kecenderungan arah pada keterampilan pengucapan kata pada pola kata KVK saat kondisi baseline awal (A1) arah datanya mengalami peningkatan (+). Pada kondisi intervensi (B) arah datanya (+). Pada kondisi baseline kedua (A2) arah datanya (+).Maka dapat dimaknai bahwa keterampilan pengucapan kata dengan pola KVK bagi anak berkesulitan belajar meningkat dan menunjukkan efek yang positif setelah adanya perubahan setelah diberikan intervensi dengan menggunakan model pembelajaran CIRC. Untuk menentukan level perubahan pada ketiga kondisi (baseline A1, intervensi dan baseline A2 ) maka data point terakhir pada kondisi baseline (A1) adalah 30 dan data point pertama pada kondisi intervensi adalah 50. Selisih antara keduanya yaitu $50-30=20(+)$, ini berarti level perubahan kondisi baseline (A1) sampai kepada kondisi awal intervensi meningkat. Data point terakhir saat kondisi intervensi (B) adalah 70 dan data pertama pada kondisi baseline (A2) adalah 60. Selisih antara keduanya yaitu 70-60 $=10(+)$, ini berarti ini berarti level perubahan dari kondisi baseline (A1) 
392 Keterampilan Pengucapan Kata Melalui Model Pembelajaran Cooperative Integrated Reading and Composition bagi Anak Berkesulitan Belajar - Fifi Melani Putri, Marlina Marlina

DOI: https://doi.org/10.31004/basicedu.v5i1.666

sampai kepada kondisi awal intervensi mengalami peningkatan.

Selanjutnya pada grafik 1.5 kecenderungan arah pada keterampilan pengucapan kata pada pola kata VKVK saat kondisi baseline awal (A1) arah datanya mengalami peningkatan (+). Pada kondisi intervensi (B) arah datanya mengalami peningkatan (+). Pada kondisi baseline kedua (A2) arah datanya juga mengalami peningkatan (+). Maka dapat dimaknai bahwa keterampilan pengucapan kata VKVK bagi anak berkesulitan belajar meningkat dan menunjukkan efek yang positif setelah adanya perubahan setelah diberikan intervensi dengan menggunakan model pembelajaran CIRC. Selanjutnya data point terakhir pada kondisi baseline (A1) adalah 20 dan data point pertama pada kondisi intervensi adalah 50. Selisih antara keduanya yaitu $50-20=30(+)$, ini berarti level perubahan kondisi baseline (A1) sampai kepada kondisi awal intervensi meningkat. Selanjutnya data point terakhir pada pola kata VKVK saat kondisi intervensi (B) adalah 80 dan data pertama pada kondisi baseline (A2) adalah 60. Selisih antara keduanya pada yaitu $80-60=$ 20(+), ini berarti level perubahan dari kondisi baseline (A1) sampai kepada kondisi awal intervensi mengalami peningkatan.

Kecenderungan arah pada keterampilan pengucapan kata pada pola kata KVKVK saat kondisi baseline awal (A1) mengalami peningkatan (+). Pada kondisi intervensi (B) arah datanya (+). Pada kondisi baseline kedua (A2) arah datanya juga mengalami peningkatan (+). Maka dapat dimaknai bahwa keterampilan pengucapan kata dengan pola KVKVK bagi anak berkesulitan belajar meningkat dan menunjukkan efek yang positif setelah adanya perubahan setelah diberikan intervensi dengan menggunakan model pembelajaran CIRC. Dan data point terakhir pada kondisi baseline (A1) adalah 30 dan data point pertama pada kondisi intervensi adalah 0. Selisih antara keduanya yaitu 30-0=30(+), ini berarti level perubahan kondisi baseline (A1) sampai kepada kondisi awal intervensi meningkat. Data point terakhir saat kondisi intervensi (B) adalah 90 dan data pertama pada kondisi baseline (A2) adalah 70. Selisih antara keduanya yaitu 90-70 $=20(+)$, ini berarti level perubahan dari kondisi baseline (A1) sampai kepada kondisi awal intervensi mengalami peningkatan.

Persentase overlape pada pola kata KVK kondisi baseline (A1) dengan intervensi adalah sebesar 0\%, dan kondisi intervensi dengan baseline (A2) persentasenya adalah 25\%. Selanjutnya persentase overlap padapola kata VKVK kondisi baseline (A1) dengan intervensi adalah sebesar $12,50 \%$, dan kondisi intervensi dengan baseline (A2) persentasenya adalah $25 \%$. Dan persentase overlape pada pola kata KVKVK kondisi baseline (A1) dengan intervensi adalah sebesar 0\%, dan kondisi intervensi dengan baseline (A2) persentasenya adalah 37,5\%. Maka dari itu semakin kecil persentase overlape, maka akan semakin baik pengaruh intervensi atau perubahan tingkah laku.

\section{Pembahasan}

Berdasarkan hasil penelitian diketahui bahwa pemberian intervensi model pembelajaran CIRC dapat meningkatkan keterampilan 
393 Keterampilan Pengucapan Kata Melalui Model Pembelajaran Cooperative Integrated Reading and Composition bagi Anak Berkesulitan Belajar - Fifi Melani Putri, Marlina Marlina

DOI: https://doi.org/10.31004/basicedu.v5i1.666

pengucapan kata anak berkesulitan belajar. Penelitian ini memerlukan kerjasama tim dalam membantu anak kesulitan belajar mkembaca kata. Hal terpenting dalam penggunaan model pembelajaran CIRC yaitu kerjasama kelompok dan kekompakkan anggota kelompok dalam memecahkan soal. Pada saat belajar anak berkesulitan belajar digabungkan dengan anak yang sudah lancar dalam membaca. Kemudian anak yang sudah lancar membaca membantu anak kesulitan belajar dalam membaca kata.

Langkah awal dalam menerapkan model pembelajaran CIRC yaitu menbentuk kelompok yang beranggotakan 4 orang peserta didik dengan kemampuan yang heterogen. Peserta didik dikelompokkan berdasarkan peringkat dikelas. Hal ini dilakukan oleh peneliti dengan syarat peserta didik setuju mengikuti proses pembelajaran sampai selesai dan mau bekerjasama membantu anak kesulitan belajar dalam membaca. Dalam menerapkan model pembelajaran CIRC siswa saling berdiskusi memecahkan soal yang diberikan guru. Hasil diskusi dibacakan oleh anak kesulitan belajar di depan kelas. Kemudian peserta didik saling membantu anak kesulitan belajar jika dalam membaca kata anak kesulitan belajar masih belum tepat. Seluruh siswa diberi pengertian oleh guru bahwa tidak boleh mencemooh dan mendiskriminasi teman dalam belajar.

Pada penelitian ini menunjukkan adanya peningkatan persentase anak kesulitan belajar dalam mengucapkan kata setelah diberikannya intervensi berupa model pembelajaran CIRC. Dikatakan meningkat karena setelah diberikan intrvensi anak kesultan belajar tidak menambahkan huruf lagi pada kata yang dibaca. Selama ini keterampilan mengucapkan kata anak kesulitan belajar rendah kt arena kurangnya motivasi dalam belajar dan lingkungan yang kurang mendukung.

Penelitian ini relevan dengan penelitian sebelumnya (Durukan, 2011) yang menyatakan bahwa model pembelajaran CIRC dapat meningkatkan keterampilan peserta didik dalam membaca. Dengan model pembelajaran CIRC anak kesulitan belajar lebih bersemangat dalam belajar dan anak menjadi tahu kesalahan yang dilakukan tiap membaca serta merasa lebih diperhatikan oleh teman-teman dikelas.

\section{SIMPULAN}

Model pembelajaran CIRC merupakan suatu bentuk proses belajar yang dilakukan secara bersama-sama atau berkelompok dengan tujuan menyelesaikan suatu persoalan atau permasalahan agar tujuan bersama dapat tercapai. Berdasarkan hasil analisis data maka dapat disimpulkan bahwa penggunaan model pembelajaran CIRC dapat meningkatkan keterampilan pengucapan kata bagi anak berkesulitan belajar. Dari analisis secara keseluruhan menunjukkan adanya peningkatan keterampilan pengucapan kata anak berkesulitan belajar. Berdasarkan temuan-temuan diatas dapat disimpulkan bahawa penggunaan model pembelajaran dapat meningkatkan keterampilan pengucapan kata anak berkesulitan belajar di SD N 34 Siguntur Tua.

\section{DAFTAR PUSTAKA}

Durukan, E. (2011). Effects of Cooperative Integrated Reading and Composition (CIRC) Technique on Reading-Writing Skills. 
394 Keterampilan Pengucapan Kata Melalui Model Pembelajaran Cooperative Integrated Reading and Composition bagi Anak Berkesulitan Belajar - Fifi Melani Putri, Marlina Marlina

DOI: https://doi.org/10.31004/basicedu.v5i1.666

Educational Research and Reviews, 6(1), 102-109.

Gupta, M., \& Ahuja, J. (2014). Cooperative Integrated Reading Composition (CIRC): Impact on Reading Comprehension Achievement in English Among Seventh Graders. International Journal of Research in Humanities, Arts and Literature Journals, 2(5), 37-46.

Jaedun, A. (2011). Metodologi Penelitian Eksperimen. Fakultas Teknik UNY, 12.

Marlina, M. (2015). Asesmen Anak Berkebutuhan Khusus: Pendekatan Psikoedukasional Edisi Revisi.

Marlina, M. (2019). Asesmen Kesulitan Belajar (1st ed.). Jakarta: Prenadamedia Group.

Novembli, M. S., Marlina, M., \& Martias, M. (2015). Layanan Proses Pembelajaran pada Anak Berkesulitan Belajar. Jurnal Penelitian Pendidikan Khusus, 4(1).

Shoimin, A. (2016). 68 Model Pembelajaran Inovatif dalam Kurikulum 2013. Yogyakarta: Ar-Ruzz Media.

Tristiantari, N. K. D., \& Sumantri, I. M. (2016). Model Pembelajaran Cooperatif Integrated Reading Composition Berpola Lesson Study Meningkatkan Keterampilan Membaca dan Menulis. JPI (Jurnal Pendidikan Indonesia), 5(2), 203-211.

Yantini, M. A., Sudiara, I. N. S., \& Astika, I. M. (2014). Penerapan Model Pembelajaran Cooperative Integrated Reading and Composition (CIRC) untuk Meningkatkan Kemampuan Membaca Responsif pada Siswa Kelas VIII. I SMP Negeri 1 Gerokgak. Jurnal Pendidikan Bahasa Dan Sastra Indonesia Undiksha, 2(1). 